\title{
A CONCEPTUAL MODEL FOR IFC-BASED DELINEATION OF CONDOMINIUM RIGHTS IN TURKEY: INITIAL EXPERIMENTS
}

\author{
D. Guler*, T. Yomralioglu \\ Department of Geomatics Engineering, Istanbul Technical University, 34469, Istanbul, Turkey \\ (gulerdo, tahsin)@itu.edu.tr
}

KEY WORDS: Building Permit, Condominium, 3D Land Administration, BIM, IFC.

\begin{abstract}
:
Owing to the increasing existence of multistorey buildings and infrastructures in the built environment, there is a need for threedimensional (3D) land administration systems (LAS). Regarding this, condominium rights in real-estate properties are needed to be represented as 3D for preventing misinterpretations with regards to who is responsible for or has ownership in which parts of the buildings. Digitalizing the public services appears in current strategies of governments and administrations since it contributes to transparency, speed, and accurateness in the processes. Building permitting that contains obtaining the occupancy permit is a vital one of these public services. With the even-increasing adaptation of Building Information Modelling (BIM), a whole raft of Building Information Models (BIMs) are created to use in digital building permitting. Thus, a significant opportunity for 3D delineation of condominium rights comes out of the reuse of these BIMs, especially their Industry Foundation Classes (IFC) data. In this sense, this paper puts forward an approach that includes developing the conceptual model to depict condominium rights and linking that model with the IFC schema. The applicability of the approach is demonstrated by using a floor of a simple building. The study shows that IFC-based representation of condominium rights can be beneficial for the transition to 3D LAS in Turkey.
\end{abstract}

\section{INTRODUCTION}

Digitalization is one of the important issues that governments and administrations aim to extend its use for the management of the built environment (European Union, 2019) because it facilitates the procedures and reaching the information in a broad range of services such as building permit issuing (Noardo et al., 2020b) and cadastral registration (Gulliver et al., 2017). The building permit issuing is currently realized based on hard copies or PDF files, and the procedures regarding building permitting are done manually. This might cause slow reviewing, insufficient feedback, and heavy workload (Malsane et al., 2015). In order to increase the efficiency of the building permit issuing, digitalization and automation are seen as pivotal components. These components are more applicable these days thanks to Building Information Modelling (BIM). This is because BIM provides the object-based modelling of parts of the buildings by storing their semantic and spatial information together for the whole lifecycle including design, construction, and management (Teicholz et al., 2018). The adaptation of BIM has grown in the countries over the years, for example in United Kingdom (UK) (NBC, 2020) and Turkey (BIMgenius, 2020). With the everincreasing use of BIM in different sectors, especially in Architecture, Engineering, and Construction (AEC) sector, threedimensional (3D) digital models of buildings are more available today. OpenBIM standards are developed by the buildingSMART to enable efficient data exchange between various stakeholders such as architects, engineers, and managers who take part in the lifecycle of buildings and infrastructures (buildingSMART, 2021a). There are different standards, namely Industry Foundation Classes (IFC), Information Delivery Manual (IDM), BIM Collaboration Format (BCF), and Model View Definitions (MVD). IFC (ISO, 2018) and IDM (ISO, 2016) that includes MVD are International Organization for Standardization (ISO) standards. IFC that makes possible the interoperability between different software, applications, and tools provides comprehensive data schema (buildingSMART, 2021b).
Different countries around the world such as Singapore, Norway, and Australia developed systems that enable automatic compliance checking based on BIM in the context of building permitting (Eastman et al., 2009). Researchers proposed to use the Building Information Models (BIMs), particularly IFC files, in building permit procedures. Some of the studies demonstrated how to benefit from visual programming languages (Ghannad et al., 2019) or natural language processing techniques (Zhang and El-Gohary, 2017) in order to transfer rules in building codes to machine-readable format. In the sense of Turkey, there is no exist so much study that principally focuses on the digitalization and automation of building permit issuing. However, for example, Macit İlal and Günaydın (2017) proposed a hybrid model that enables the computer representation of building codes. They showed the implementation of the proposed model using rules in the Izmir Municipality Housing and Zoning Code. Recently, Aydin (2021) developed a web-based system that performs the code checking using BIMs according to Planned Areas Zoning Regulation (PAZR) in Turkey.

Building permitting is very essential for creating a safe built environment. When it comes to ensuring the sustainability of the built environment, land administration that has four main parts, namely land registry, cadastre, valuation, and land use planning is of paramount importance (Williamson et al., 2010). Land administration systems (LAS) are commonly implemented based on two-dimensional (2D) data and representations (Kalogianni et al., 2020). Yet there is a need for 3D land administration that allows to unambiguously delineate the property rights since dense areas and complex infrastructures are increasing in the built environment day by day. Putting into practice the 3D LAS requires the integration of different disciplines and stakeholders (van Oosterom et al., 2020). The international standards that permit interoperability are therefore of significance. Accordingly, a great number of studies concentrated on how to exploit these standards for 3D representation of ownership rights

\footnotetext{
${ }^{*}$ Corresponding author
} 
(van Oosterom, 2018). Some of these studies proposed to use the Land Administration Domain Model (LADM) (Kalogianni et al., 2021). Some scholars researched the integration of LADM with other standards such as CityGML (Li et al., 2016) and IndoorGML (Alattas et al., 2017) in order to better model legal rights and their physical counterparts. An ADE for CityGML that includes delineation of condominium rights in Turkey is also proposed (Cagdas, 2013). With the growing interest in BIM, numerous researchers focused on the use of it in the context of 3D cadastre for different countries; for example, Sweden (Sun et al., 2019), Australia (Barzegar et al., 2021), and Serbia (Sladić et al., 2020). Recently, Atazadeh et al. (2021) proposed to use the IFC schema for modelling the features and attributes in LADM. Alattas et al. (2021) developed an approach that integrates IFC and LADM to represent the legal spaces in properties in Saudi Arabia. Celik Simsek and Uzun (2021) proposed to calculate the property valuations based on BIMs in the sense of condominium ownership in Turkey. Guler and Yomralioglu (2021) suggested a conceptual framework for Turkey that integrates digital building permitting and 3D representation of condominium rights in terms of the use of BIMs.

In light of this information, the objective of this paper is to show the possible reuse of as-built BIMs that are approved in building permit issuing for the $3 \mathrm{D}$ delineation of condominium rights in Turkey, based on the IFC schema. In this sense, this paper first proposes a conceptual model for 3D delineation of condominium rights, and then it shows an example by matching the features and attributes in this model with IFC schema. It is expected that this paper forms a basis for complete 3D representation and registration of condominium rights in the Turkish cadastre using IFC data.

\section{CONNECTION BETWEEN BUILDING PERMIT ISSUING AND REGISTRATION OF CONDOMINIUM RIGHTS}

In Turkey, it should be gotten a building permit to start new construction. This issue is mandated in Zoning Law (Official Gazette, 1985). Every firm applies to a responsible local agency or municipality with required documents in building permit submission. These documents include architectural project, static project, and title deed. The submissions are done using paperbased documents or PDF files generally. E-submission platforms have been started to use in the past few years. Controlling the compliance of building designs in regards to rules in regulations is manually realized in general. If everything is proper, the building permit is prepared. After that, the construction can be started. It is also mandated that every building should be inspected during construction to check whether they are built in accordance with specifications in the approved building permit.

Once the construction is completed, it should be applied same responsible local agency or municipality to get an occupancy permit. If the building has not an occupancy permit, it cannot benefit from public services such as natural gas and electricity. The condominium is a special type of ownership. Condominium Law is the main law in Turkey that provides legal infrastructure related to the condominium (Official Gazette, 1965). According to the second article of this law, the whole property that is subject to the condominium is defined as the main property, and only the structural part of the main property is defined as the main building. In the same article, a condominium unit is defined as parts of the main property that are suitable to be used independently and are subject to the condominium according to this law. The place locates in the outer of the condominium unit and is directly allocated to that condominium unit is defined as an annex. Coal cellar, water tank, and garage are given as an example for an annex in the sixth article of this law. The places locate in the outer part of condominium units and serve for protection and jointly use or benefit are defined as common facilities. Main walls, common walls that separate the condominium units, patios, main entrance doors, stairs, elevators, corridors are given as an example for common facilities in the fourth article of this law.

It is stated in the tenth article of Condominium Law that the occupancy permit and approved architectural project are used in the registration of condominium rights. It can thus be said that there is a connection between building permit issuing and registration of condominium rights in Turkey. This connection can be enhanced from the point of view of digitalization because the use of BIM is significantly increasing in the AEC industry day by day. BIMs have important potential in the digitalization and automation of building permit issuing. Since BIMs can store detailed spatial and semantic information about buildings, they can be used for compliance checking in building permit procedures. Moreover, the as-built BIMs of buildings can be obtained and used for the representation of condominium rights instead of computer-aided design (CAD) drawings or PDF files. In other words, the misapplications in registration of condominium rights that might result from the use of only an architectural project that is used in building permit submission can be prevented, since the up-to-date model of the building that is updated during construction is used.

\section{A CONCEPTUAL MODEL FOR REPRESENTATION OF CONDOMINIUM RIGHTS}

The workflow implemented in this study is shown in Figure 1. As can be seen from Figure 1, the first step is to create a conceptual model for the representation of condominium rights. It is important to compose a conceptual model that meets the requirements for a 3D Turkish cadastre in the context of features and attributes to realize the efficient physical model. The second and third steps of workflow consist of obtaining the drawing plan of a floor and 3D modeling of a floor in a building using BIM authoring to exemplify the proposed approach in this paper. However, it can be assumed that these two steps are omitted in the real-world application because the as-built BIM of the constructed building will be existing.

The international standards and national projects in Turkey are taken into account in generating the conceptual model. LADM (ISO, 2012) that provides a common basis for the implementation of land administration related activities is the most widely-used standard across the globe. It is an ISO standard. A great number of researchers created country profiles that meet the requirements for land administration systems in their countries, based on the LADM; for example, Croatia (Vučić et al., 2017), Morocco (Adad et al., 2020), and China (Zhuo et al., 2015). There are four basic classes in LADM, namely LA_Party, LA_RRR, LA_BAUnit, and LA_SpatialUnit as shown in Figure 2. LA_LegalSpaceBuildingUnit, as a subclass of LA_SpatialUnit, enables the modeling of legal spaces in buildings that need to be represented distinctively as they do not overlap with physical structures in any case.

Turkey National Geographic Information System (TNGIS, in Turkish TUCBS) project, which is carried out by the General Directorate of Geographic Information Systems (GDoGIS), aims to create complete spatial data infrastructure for the country in order to ensure interoperability between stakeholders that produce and benefit from spatial data. In this sense, the 
conceptual models are created for various themes such as cadastre, building, and infrastructure, and the application schemas of these themes that enable spatial data exchange efficiently are produced (GDoGIS, 2020). These conceptual models are created based on international standards, e.g., LADM. Besides, they are formed as compatible with data standards such as CityGML and IndoorGML to be used in urban management applications.

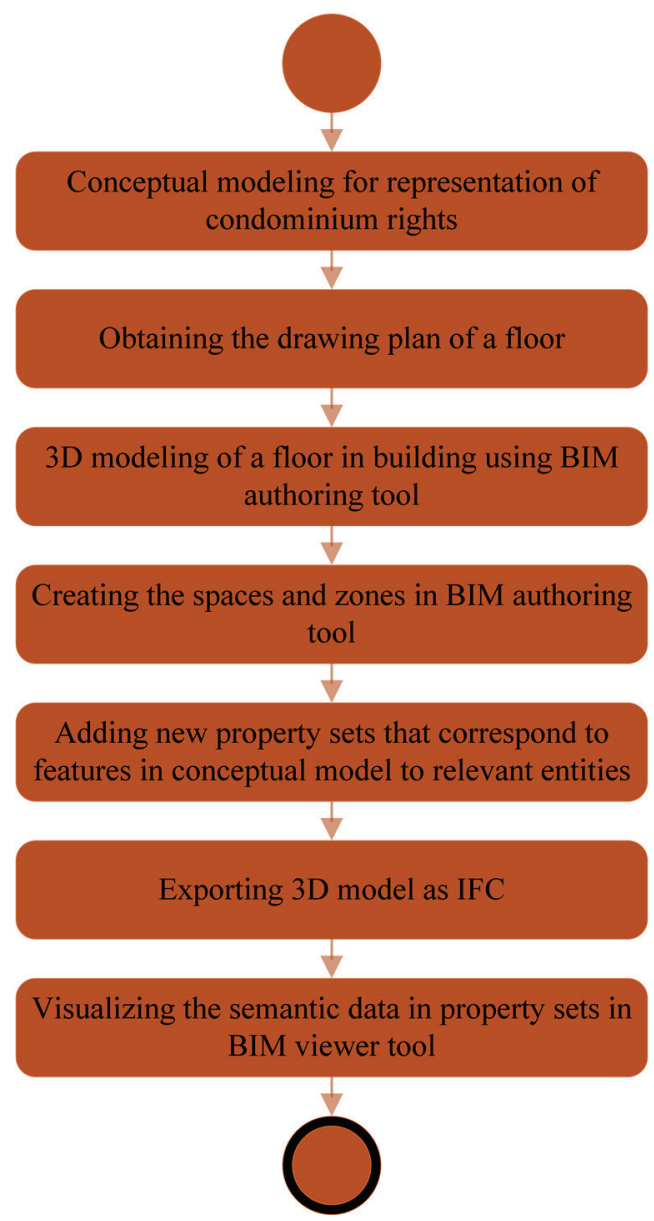

Figure 1. The workflow implemented in this study.

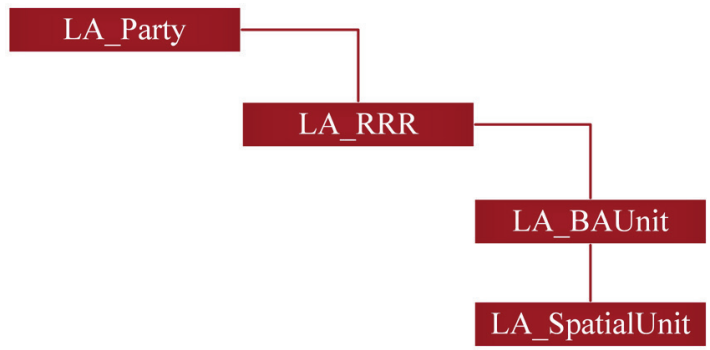

Figure 2. Basic classes of LADM (ISO, 2012).

Figure 3 shows the conceptual model used in this study. This model is generated by considering the TNGIS Building and Cadastre themes and LADM so as to represent the condominium rights as 3D. TR Owner is used to express interest holder that has ownership. $\bar{T} R \_$RRR shows the relevant attributes with respect to rights, restrictions, and responsibilities (RRR). TR RegistrationUnit represents the basic administrative unit that is defined legally. TR_Parcel has attributes related to the parcel. TR Building stores the attributes regarding the registered building. TR_Annex is used to express accessory parts in a building. TR_CommonFacility represents the common places in a building. TR CondominiumUnit is used to model apartments in the building. TR_Building can have TR_CondominiumUnit depending on whether the condominium is established.

\section{IFC-BASED IMPLEMENTATION OF CONCEPTUAL MODEL}

Once the conceptual model is generated, the next step is to find a suitable way that allows to expression of the features and attributes in that model using the IFC schema. IFC specification that contains terms, concepts, and data characteristics is published by buildingSMART. There are two official versions right now, namely IFC2x3 TC1 and IFC4 ADD2 TC1. IFC2x3 $\mathrm{TC} 1$ is the most widely adopted version by BIM authoring tools, for example, Autodesk Revit. IFC4 ADD2 TC1 is being tried to adopt by different tools. In this paper, the conceptual model is mapped with entities and data types based on the IFC4 ADD2 $\mathrm{TC} 1$ version. Besides, created BIM model is exported as an IFC $2 \times 3 \mathrm{TC} 1$ version to compare two versions. Entities in the IFC schema can be enriched by adding new property sets to them. These property sets can have attributes that are formed by the creator. In order to depict the features and attributes in the conceptual model, new property sets and their properties (i.e., attributes) are defined. Table 1 itemizes property sets, properties, property types, and data types used in this study. Two IFC entities, namely IfcSpace and IfcZone are used to model the condominium rights. IfcSpace can represent the legal spaces with respect to a condominium unit, annex, and common facility. IfcZone that can have multiple IfcSpace instances is used to depict the registration unit that might have both condominium unit and annex at the same time. Figure 4 shows the hierarchy in the IFC schema with regards to IfcSpace and IfcZone entities.

Different property types that are defined in the IFC schema can be used to model attributes (i.e., properties) in the property sets. Whereas IfcPropertySingleValue is used to express attributes that have single-type value, IfcPropertyEnumeratedValue is used to represent attributes that might have a value that can be selected from an already defined list. For example, the type of annex can be labeled as a garage in the IFC file by selecting from the enumeration list. After mapping the conceptual model with the IFC schema, a floor of a simple building is used to present the implementation of the proposed approach.

First, the floor is modeled in the BIM authoring tool. Second, new property sets and attributes are created. Third, the spaces and zones are defined in the model. Fourth, the attributes are populated with information. Fifth, the model is exported as IFC. Due to BIM authoring tools do not permit to easily visualize semantic information of entities in the model, two IFC viewers, namely Solibri Anywhere and BIMvision that are free are used to visualize the exported IFC file. Figure 5 shows an annex that is modeled as legal space by using IfcSpace and its attributes. In this example, the type of annex is storage. 


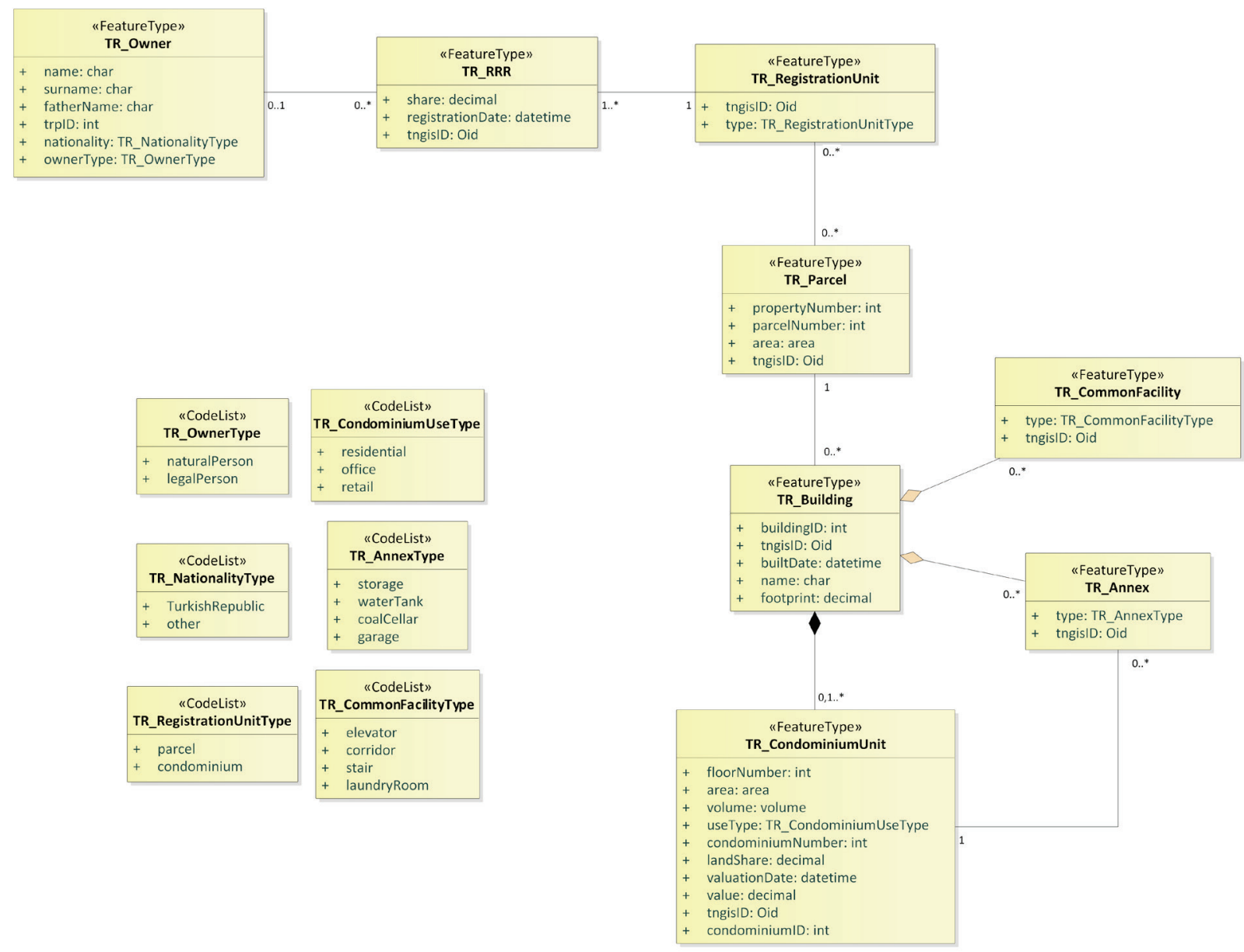

Figure 3. The conceptual model used to represent the condominium rights.

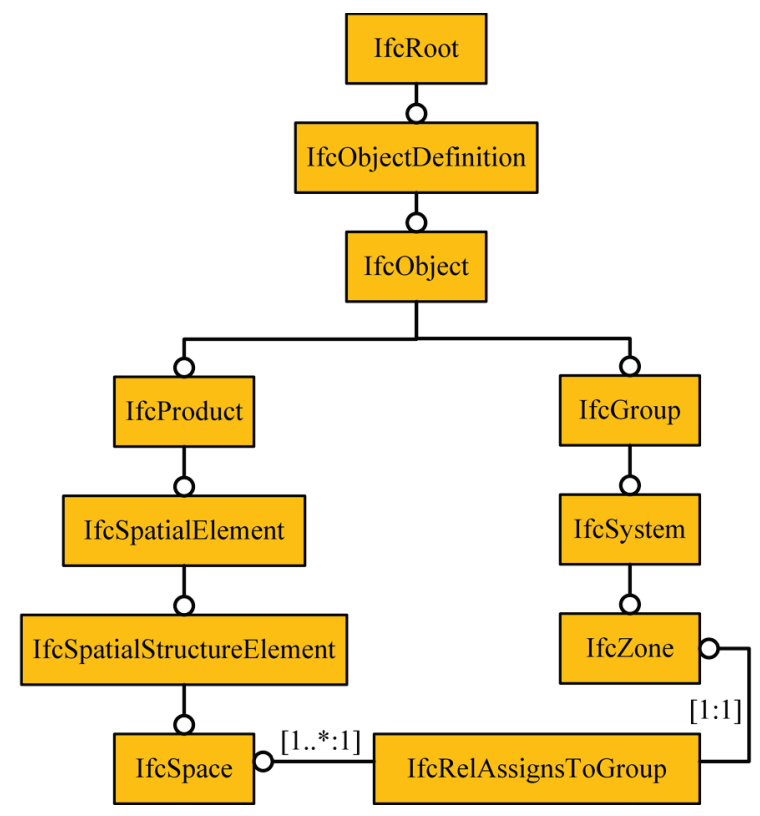

Figure 4. Hierarchy in the IFC schema.

Figures 6 and 7 present two modelling examples for common facilities that are labeled as elevator and corridor, respectively.

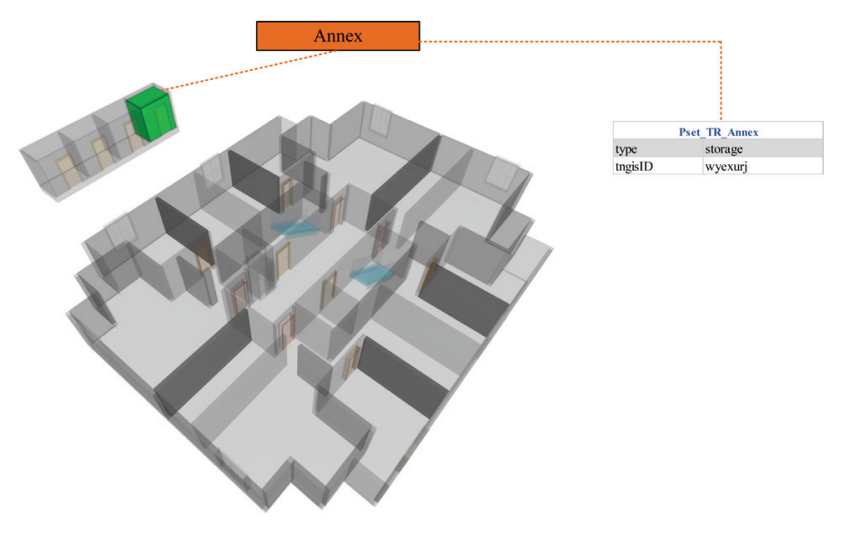

Figure 5. Modelled annex.

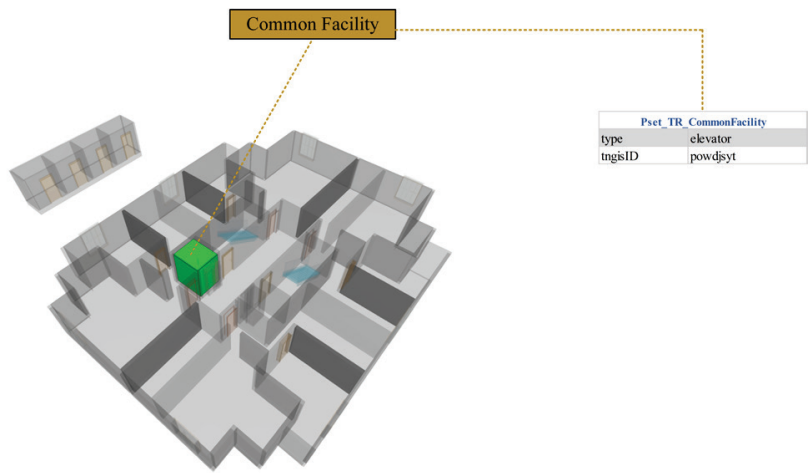

Figure 6. Modelled elevator as a common facility. 


\begin{tabular}{|c|c|c|c|}
\hline Property Set Name & Property Name & Property Type & Data Type \\
\hline \multirow[t]{6}{*}{ Pset_TR_Owner } & name & IfcPropertySingleValue & IfcLable \\
\hline & surname & IfcPropertySingleValue & IfcLable \\
\hline & fatherName & IfcPropertySingleValue & IfcLable \\
\hline & trpID & IfcPropertySingleValue & IfcIdentifier \\
\hline & nationality & IfcPropertyEnumeratedValue & IfcLable \\
\hline & ownerType & IfcPropertyEnumeratedValue & IfcLable \\
\hline \multirow{3}{*}{ Pset_TR_RRR } & share & IfcPropertySingleValue & IfcReal \\
\hline & registrationDate & IfcPropertySingleValue & IfcDateTime \\
\hline & tngisID & IfcPropertySingleValue & IfcIdentifier \\
\hline \multirow{2}{*}{ Pset_TR_RegistrationUnit } & tngisID & IfcPropertySingleValue & IfcIdentifier \\
\hline & type & IfcPropertyEnumeratedValue & IfcLable \\
\hline \multirow{4}{*}{ Pset_TR_Parcel } & propoertyNumber & IfcPropertySingleValue & IfcInteger \\
\hline & parcelNumber & IfcPropertySingleValue & IfcInteger \\
\hline & area & IfcPropertySingleValue & IfcAreaMeasure \\
\hline & tngisID & IfcPropertySingleValue & IfcIdentifier \\
\hline \multirow[t]{5}{*}{ Pset_TR_Building } & buildingID & IfcPropertySingleValue & IfcInteger \\
\hline & tngisID & IfcPropertySingleValue & IfcIdentifier \\
\hline & builtDate & IfcPropertySingleValue & IfcDateTime \\
\hline & name & IfcPropertySingleValue & IfcLable \\
\hline & footprint & IfcPropertySingleValue & IfcReal \\
\hline \multirow[t]{10}{*}{ Pset_TR_CondominiumUnit } & floorNumber & IfcPropertySingleValue & IfcInteger \\
\hline & area & IfcPropertySingleValue & IfcAreaMeasure \\
\hline & volume & IfcPropertySingleValue & IfcVolumeMeasure \\
\hline & useType & IfcPropertyEnumeratedValue & IfcLable \\
\hline & condominiumNumber & IfcPropertySingleValue & IfcInteger \\
\hline & landShare & IfcPropertySingleValue & IfcLable \\
\hline & valuationDate & IfcPropertySingleValue & IfcDateTime \\
\hline & value & IfcPropertySingleValue & IfcReal \\
\hline & tngisID & IfcPropertySingleValue & IfcIdentifier \\
\hline & condominiumID & IfcPropertySingleValue & IfcInteger \\
\hline \multirow[t]{2}{*}{ Pset_TR_CommonFacility } & type & IfcPropertyEnumeratedValue & IfcLable \\
\hline & tngisID & IfcPropertySingleValue & IfcIdentifier \\
\hline \multirow[t]{2}{*}{ Pset_TR_Annex } & type & IfcPropertyEnumeratedValue & IfcLable \\
\hline & tngisID & IfcPropertySingleValue & IfcIdentifier \\
\hline
\end{tabular}

Table 1. Property set names, property names, property types, and data types that are used to depict the conceptual model.

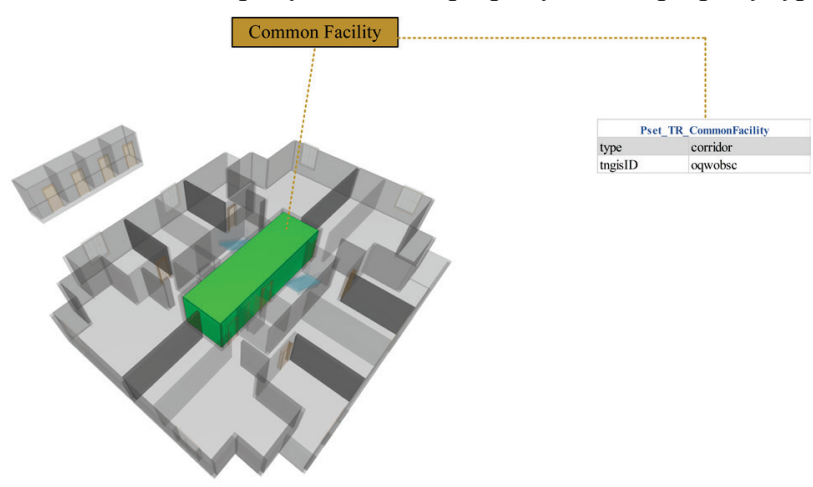

Figure 7. Modelled corridor as a common facility.

Figure 8 shows a condominium unit that is modelled by using IfcSpace. As can be seen from the figure, all attributes in the conceptual model are defined through Pset_TR_CondominiumUnit. Figure 9 illustrates a registration unit example that has a condominium unit and storage that is allocated to its use. IfcZone entity is used to depict the registration unit since it allows to model the combination of more than one space.

\section{DISCUSSION AND FUTURE WORK}

This paper first proposes a conceptual model for modelling condominium rights and then it maps features and their attributes by creating new property sets that use proper property types and data types in the IFC schema. It is important to note that new property sets can be created in different ways. One way is to create new property sets within the BIM authoring tool. However, creating new property sets differ from the tool in terms of the property and data types that are permitted to generate. For example, while the ArchiCAD allows selecting enumeration as property type, this is not possible in Autodesk Revit. Another way is to use the tools that permit to manipulate IFC files using predefined functions. For example, new property sets and their attributes can be created using the Xbim toolkit that is an opensource tool. The semantic data can be also populated by benefiting from the Xbim toolkit.

Another important issue is that BIM authoring tools and BIM viewers might have not full support for the latest official IFC version. This might interrupt the efficient use of the IFC. However, open-source tools such as the Xbim toolkit can be used to enrich IFC files as it supports the latest version of the IFC, namely IFC4 ADD2 TC1. BlenderBIM Add-on that is developed as an extension for Blender to create and manipulate IFC files also supports the IFC4 schema. It is also useful to note that new data types in IFC schema, for example, IfcDateTime, enable to store values more specifically. IfcDateTime can be used as a data type for registration date and valuation date instead of IfcText. 


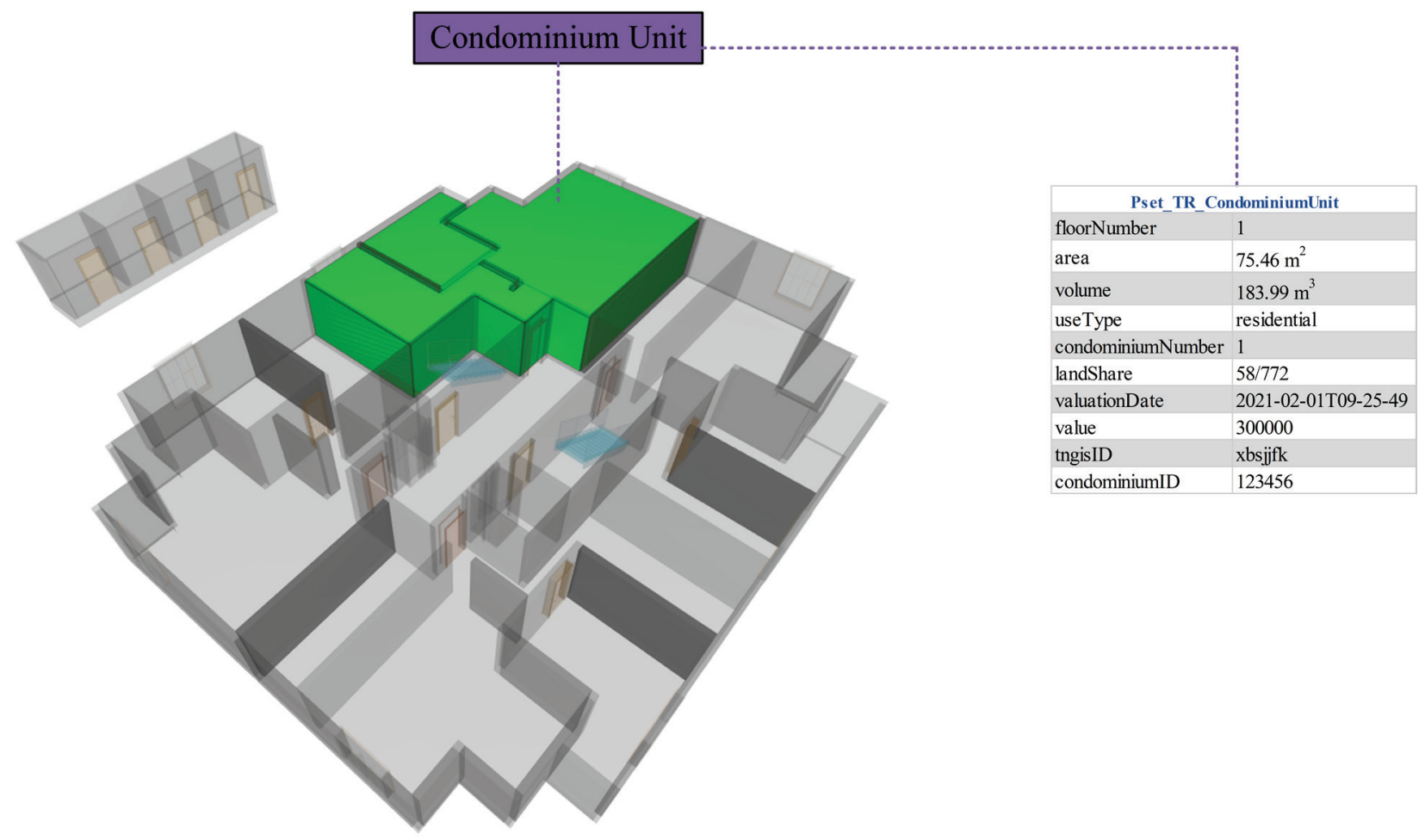

Figure 8. Modelled condominium unit.

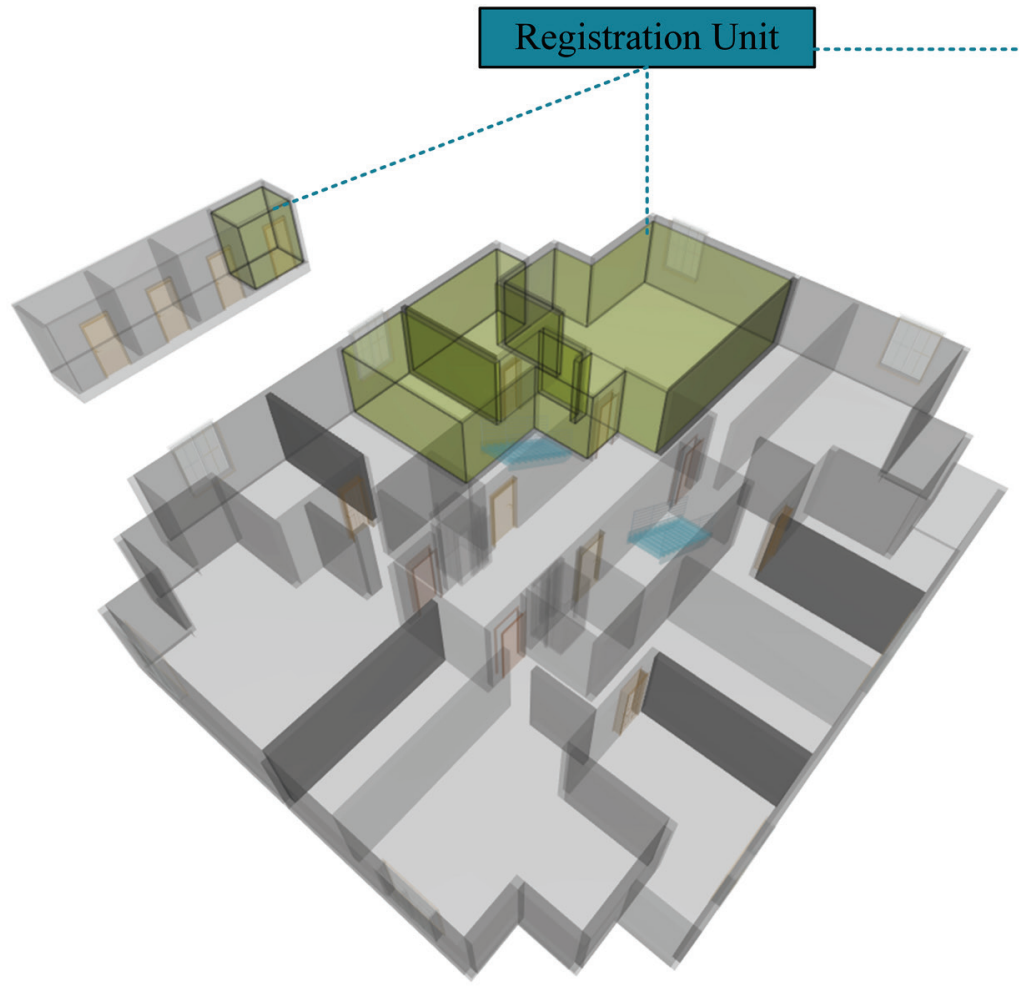

\begin{tabular}{|c|c|}
\hline \multicolumn{2}{|c|}{ Pset_TR_RegistrationUnit } \\
\hline tngisID & xdfgiulk \\
\hline type & condominium \\
\hline \multicolumn{2}{|c|}{ Pset_TR_Owner } \\
\hline name & Ayșe \\
\hline surname & Birinci \\
\hline fatherName & Ahmet \\
\hline trpID & 12345678900 \\
\hline nationality & TurkishRepublic \\
\hline ownerType & naturalPerson \\
\hline \multicolumn{2}{|c|}{ Pset_TR_RRR } \\
\hline share & 1 \\
\hline registrationDate & 2013-12-02T15-12-56 \\
\hline tngisID & yruyrif \\
\hline
\end{tabular}

Figure 9. Modelled registration unit.

Due to the fact that more BIMs are available, there is a need for guidelines that describe the necessary information that the BIM model should have, in order to ensure efficient data exchange between various stakeholders. In doing so, IFC files that can be used to model condominium rights within the context of land administration will be provided. In this sense, MVD can be a powerful solution. From the GeoBIM point of view, it is significant to benefit from IFC files for creating or updating the
3D city and built environment models. These models are very crucial because they form the basis for smart cities and LAS in terms of the use of spatial data. At this point, it should be paid attention to achieve correct georeferencing when both modeling the condominium rights based on the IFC and converting it to CityGML (Noardo et al., 2020a). The reuse of as-built BIMs for 3D land administration is seen as a very promising opportunity because they enable to model the property rights and their 
physical counterparts with required semantic data. To benefit from this opportunity, a more detailed investigation regarding $3 \mathrm{D}$ land administration practices in Turkey is needed. For this reason, future work will contain the examination on extending the IFC schema such that it meets the requirements for the transition to 3D LAS in Turkey.

\section{ACKNOWLEDGEMENTS}

This work is supported by the Scientific Research Projects Department of Istanbul Technical University. Project Number: MDK-2019-42092.

\section{REFERENCES}

Adad, M.A., Semlali, E.H., El-Ayachi, M., Ibannain, F., 2020. Supporting land data integration and standardization through the LADM standard: Case of Morocco's country profile MALADM. Land Use Policy, 97, 104762. doi.org/10.1016/j.landusepol.2020.104762

Alattas, A., Kalogianni, E., Alzahrani, T., Zlatanova, S., van Oosterom, P., 2021. Mapping private, common, and exclusive common spaces in buildings from BIM/IFC to LADM. A case study from Saudi Arabia. Land Use Policy, 104, 105355. doi.org/10.1016/j.landusepol.2021.105355

Alattas, A., Zlatanova, S., Van Oosterom, P., Chatzinikolaou, E., Lemmen, C., Li, K.-J., 2017. Supporting Indoor Navigation Using Access Rights to Spaces Based on Combined Use of IndoorGML and LADM Models. ISPRS International Journal of Geo-Information, 6, 384. doi.org/10.3390/ijgi6120384

Atazadeh, B., Olfat, H., Rajabifard, A., Kalantari, M., Shojaei, D., Marjani, A.M., 2021. Linking Land Administration Domain Model and BIM environment for 3D digital cadastre in multistorey buildings. Land Use Policy, 104, 105367. doi.org/10.1016/j.landusepol.2021.105367

Aydın, M., 2021. Building Information Modeling Based Automated Building Regulation Compliance Checking Asp.net Web Software. Intelligent Automation \& Soft Computing, 28, $11-$ 25. doi.org/10.32604/iasc.2021.015065

Barzegar, M., Rajabifard, A., Kalantari, M., Atazadeh, B., 2021. An IFC-based database schema for mapping BIM data into a 3D spatially enabled land administration database. International Journal of Digital Earth, 1-30. doi.org/10.1080/17538947.2021.1875062

BIMgenius, 2020. Turkey BIM Report. https://www.bimgenius.org/uploads/6/3/9/9/63997129/bImgeni us_p0002_turkiye_bIm_raporu_2019_rev_0.pdf (7 May 2021)

buildingSMART, 2021a. Solutions and Standards. https://www.buildingsmart.org/standards/ (7 May 2021)

buildingSMART, 2021b. Industry Foundation Classes (IFC) - An Introduction. https://technical.buildingsmart.org/standards/ifc (7 May 2021)

Cagdas, V., 2013. An application domain extension to citygml for immovable property taxation: A Turkish case study. International Journal of Applied Earth Observation and Geoinformation 21, 545-555. doi.org/10.1016/j.jag.2012.07.013
Celik Simsek, N., Uzun, B., 2021. Building Information Modelling (BIM) for property valuation: A new approach for Turkish Condominium Ownership. Survey Review, 1-22. doi.org/10.1080/00396265.2021.1905251

Eastman, C., Lee, Jae min, Jeong, Y. suk, Lee, Jin kook, 2009. Automatic rule-based checking of building designs. Automation in Construction, 18, 1011-1033. doi.org/10.1016/j.autcon.2009.07.002

European Union, 2019. Supporting Digitalisation of the Construction Sector and SMEs (Including Building Information Modelling). doi.org/10.2826/422658

GDoGIS, 2020. TNGIS Application Schemas. https://tucbspublic-api.csb.gov.tr/tucbs (7 May 2021)

Ghannad, P., Lee, Y.-C., Dimyadi, J., Solihin, W., 2019. Automated BIM data validation integrating open-standard schema with visual programming language. Advanced Engineering Informatics, 40, 14-28. doi.org/10.1016/j.aei.2019.01.006

Guler, D., Yomralioglu, T., 2021. A reformative framework for processes from building permit issuing to property ownership in Turkey. Land Use Policy, 101, 105115. doi.org/10.1016/j.landusepol.2020.105115

Gulliver, T., Haanen, A., Goodin, M., 2017. A 3D digital cadastre for New Zealand and the international opportunity. ISPRS International Journal of Geo-Information, 6. doi.org/10.3390/ijgi6110375

ISO, 2018. ISO 16739-1:2018, Industry Foundation Classes (IFC) for data sharing in the construction and facility management industries - Part 1: Data schema.

ISO, 2016. ISO 29481-1:2016 Building information models Information delivery manual — Part 1: Methodology and format.

ISO, 2012. ISO 19152:2012 Geographic information — Land Administration Domain Model (LADM).

Kalogianni, E., Janečka, K., Kalantari, M., Dimopoulou, E., Bydłosz, J., Radulović, A., Vučić, N., Sladić, D., Govedarica, M., Lemmen, C., van Oosterom, P., 2021. Methodology for the development of LADM country profiles. Land Use Policy, 105, 105380. doi.org/10.1016/j.landusepol.2021.105380

Li, L., Wu, J., Zhu, H., Duan, X., Luo, F., 2016. 3D modeling of the ownership structure of condominium units. Computers, Environment and Urban Systems, 59, 50-63. doi.org/10.1016/j.compenvurbsys.2016.05.004

Macit İlal, S., Günaydın, H.M., 2017. Computer representation of building codes for automated compliance checking. Automation in Construction, 82, 43-58. doi.org/10.1016/j.autcon.2017.06.018

Malsane, S., Matthews, J., Lockley, S., Love, P.E.D., Greenwood, D., 2015. Development of an object model for automated compliance checking. Automation in Construction, 49, 51-58. doi.org/10.1016/j.autcon.2014.10.004

NBC, 2020. 10th Annual BIM Report. https://www.thenbs.com/knowledge/national-bim-report-2020 (7 May 2021) 
Noardo, F., Harrie, L., Ohori, K.A., Biljecki, F., Ellul, C., Krijnen, T., Eriksson, H., Guler, D., Hintz, D., Jadidi, M.A., Pla, M., Sanchez, S., Soini, V.P., Stouffs, R., Tekavec, J., Stoter, J., 2020a. Tools for BIM-GIS integration (IFC georeferencing and conversions): Results from the GeoBIM benchmark 2019. ISPRS International Journal of Geo-Information, 9, 502. doi.org/10.3390/ijgi9090502

Noardo, F., Malacarne, G., Mastrolembo Ventura, S., Tagliabue, L.C., Ciribini, A.L.C., Ellul, C., Guler, D., Harrie, L., Senger, L., Waha, A., Stoter, J., 2020b. Integrating Expertises and Ambitions for Data-Driven Digital Building Permits - the EUNET4DBP. International Archives of the Photogrammetry, Remote Sensing and Spatial Information Sciences - ISPRS Archives. pp. 103-110. doi.org/10.5194/isprs-archives-XLIV-4-W1-2020-103-2020

Official Gazette, $1985 . \quad$ Zoning Law. https://www.mevzuat.gov.tr/MevzuatMetin/1.5.3194.pdf(7 May 2021)

Official Gazette, 1965. Condominium Law. https://www.mevzuat.gov.tr/MevzuatMetin/1.5.634.pdf (7 May 2021)

Sladić, D., Radulović, A., Govedarica, M., 2020. Development of process model for Serbian cadastre. Land Use Policy, 98, 104273. doi.org/10.1016/j.landusepol.2019.104273

Sun, Mi, Olsson, Paulsson, Harrie, 2019. Utilizing BIM and GIS for Representation and Visualization of 3D Cadastre. ISPRS International Journal of Geo-Information, 8, 503. doi.org/10.3390/ijgi8110503

Teicholz, P., Lee, G., Eastman, C., Sachs, R., 2018. BIM Handbook: A Guide to Building Information Modeling for Owners, Designers, Engineers, Contractors, and Facility Managers, 3rd ed. John Wiley \& Sons, Inc., Hoboken, New Jersey.

van Oosterom, P. (Ed.), 2018. Best Practices 3D Cadastres Extended Version. International Federation of Surveyors (FIG), Copenhagen, Denmark.

van Oosterom, P., Bennett, R., Koeva, M., Lemmen, C., 2020. 3D Land Administration for 3D Land Uses. Land Use Policy, 98, 104665. doi.org/10.1016/j.landusepol.2020.104665

Vučić, N., Roić, M., Mađer, M., Vranić, S., van Oosterom, P., 2017. Overview of the Croatian Land Administration System and the Possibilities for Its Upgrade to 3D by Existing Data. ISPRS International Journal of Geo-Information, 6, 223. doi.org/10.3390/ijgi6070223

Williamson, I., Enemark, S., Wallace, J., Rajabifard, A., 2010. Land Administration for Sustainable Development. ESRI Press Academic, Redlands, CA.

Zhang, J., El-Gohary, N.M., 2017. Integrating semantic NLP and logic reasoning into a unified system for fully-automated code checking. Automation in Construction, 73, 45-57. doi.org/10.1016/j.autcon.2016.08.027

Zhuo, Y., Ma, Z., Lemmen, C., Bennett, R.M., 2015. Application of LADM for the integration of land and housing information in China: The legal dimension. Land Use Policy, 49, 634-648. doi.org/10.1016/j.landusepol.2015.09.005 